\title{
How Is Smart Pension Possible from the Perspective of Population Aging
}

\author{
Jingyi $\operatorname{Sun}^{1 *} \quad$ Weifeng $\mathrm{Li}^{2}$ \\ ${ }^{1,2}$ School of Political Science and Law, University of Jinan, Shandong Province, China,250022 \\ *Corresponding author. Email: $1075124893 @ q q . c o m$
}

\begin{abstract}
Under the background of aging population, the problem of providing for the aged in China has become a key issue that must be paid attention to at present. With the drawbacks of traditional old-age care increasingly exposed and the rapid development of big data and artificial intelligence, smart pension came into being. Because it is in the initial stage of development in China, it faces many challenges. This paper expounds the background and present situation of the smart pension model, and through analyzing the problems hindering its development, puts forward some countermeasures and suggestions to promote the development of the smart pension model in China from five aspects: bridging the silver digital divide, dissolving the crisis of trust, increasing the "human touch" of the old-age care, cultivating compound professionals and promoting the research and development of intelligent product technology.
\end{abstract}

Keywords: Aging, The elderly, Smart pension, Digital divide

\section{RAISING OF THE PROBLEM}

At present, China has entered a stage of rapid aging, the rapid growth of the elderly population has a great impact on the traditional pension pattern. With the transformation of the demand structure from survival to development, and driven by the diversified spiritual and emotional needs of the elderly, we need a new pension model in line with China's national conditions.

The term "smart pension" was first proposed by the British life trust, which was called "fully intelligent elderly system" at that time [3]. The concept of smart pension in China was first proposed by $\mathrm{Hu}$ liming in 2007 as "digital pension" [4]. In 2012, the National Association for the aged put forward the concept of "intelligent pension" and entered the initial stage of intelligent pension. In recent years, with the development of Internet plus pension, intelligent retirement has become an object of service for the elderly at home, and provides quick, accurate and efficient pension services for the elderly on the basis of intelligent information technology. Relying on various advanced technologies, the smart pension mode is to create a "system + service + elderly + terminal" smart pension service mode. By constructing a platform, gathering talents, information and service resources, and coordinating with various departments, a closed-loop management smart pension system is formed. From the traditional artificial to intelligent, it can realize the information exchange between the elderly and their children, service institutions and medical staff, and effectively monitor the health and safety of the elderly, which is more personalized and humanized. Old age is the key to the "Internet plus" era, and it is of great significance for the realization of active aging.

\section{THE PRACTICAL DILEMMA OF THE DEVELOPMENT OF SMART PENSION MODEL}

With the promotion and development of smart pension model in China, there are still many problems in practice. Therefore, we need to combine with the current situation of smart pension mode in our country and find out the root of it.

\section{1. "Silver Digital Divide" -- New Inequality in the Information Age}

"Silver digital divide" refers to the gap between the elderly and the younger generation in mastering and using information, and the difference between the elderly and the young in using digital information resources to try to integrate into public life [3]. The elderly are at a disadvantage in the use of intelligent products and become the most affected group under the 
digital divide. At present, the spread of code brushing, contactless payment and other methods has exposed the problem of digital divide.

On the subjective side, the majority of the elderly due to the low level of education, coupled with their own physical and psychological aging, the ability to learn new things decline, leading to operational difficulties. Especially in rural areas, the elderly are deeply affected by the economic conditions and old ideas, especially in the serious situation. In the objective aspect, first, APP Internet companies mainly attract young users to meet the needs of self survival, while ignoring the elderly group, so the products designed for the elderly are rare. The second is the lack of "suitable for aging". The relevant technology products for the elderly do not fully consider the needs of the elderly. There are problems of poor quality and cumbersome operation, which lead to the resistance of the elderly.

The problem of silver digital divide has become the crux of hindering the promotion of smart pension model in China. Efforts to fill the digital gap for the elderly is a good medicine to realize the good development of smart pension.

\section{2. "Trust Crisis" -- an Inevitable Security Risk}

In the context of the digital era of interconnection, the realization of smart pension benefits from the acquisition, sharing and utilization of data resources. The normal operation of all kinds of intelligent service devices is also based on the understanding and analysis of a large amount of data of the elderly. By capturing the real-time information, personal dynamics or all-weather monitoring of the daily life and physical condition of the elderly on the intelligent terminal device, a large amount of privacy information is stored, which is easy to be used by criminals, leading to privacy leakage, fraud, theft and other illegal and criminal acts. This not only shows that China's smart elderly care products are vulnerable in protecting data privacy, preventing illegal intrusion and other security functions, but also reflects that China's current smart service equipment data collection is scattered, data statistics lacks unified standards, and there is a lack of effective communication mechanism among suppliers, which leads to the fragmentation of demand reflected by data, and it is difficult to understand the real situation and needs of the elderly Make an accurate judgment. Therefore, in the actual operation of smart pension mode, there are many hidden dangers endangering information security.

\section{3. "Indifferent Intelligent Machine" -- Neglected Spiritual Consolation}

The existence and development of human beings is the primary task of human survival, and it is also the nature of human beings [4]. In the service of providing for the aged, we must insist on taking the elderly as the center and respect their instinct, desire, rights and needs. In old age, loneliness is more terrible than poverty. At present, our country's pension services often focus on the material needs and medical care of the elderly, ignoring the spiritual care and the need to realize self-worth, which makes the elderly lack a sense of belonging in spirit, and it is difficult to meet the diversified pension needs of the elderly. Nowadays, many intelligent machines such as chat and escort robots are criticized for their low level of intelligence and low interactivity. Therefore, the intelligent machine can not completely replace the artificial ability. Therefore, smart pension needs to be combined with humanistic care in order to provide better services for the elderly.

\subsection{Interdisciplinary Professionals -- a Rare "Magic Weapon"}

Compound professionals not only have outstanding experience in professional skills, but also have higher related skills, namely "multifunctional talents". Smart pension involves many fields, such as information technology, medical care and so on. The characteristics of the required talent team also need to achieve interdisciplinary and knowledge fusion. The elderly are still unfamiliar with intelligent machines, and need guidance and help from relevant professional and technical personnel, and can customize specific smart solutions according to the physical condition and needs of the elderly; the phenomenon of elderly living alone under the weakening of family pension function is increasing, and more and more elderly people lack the care of their children, so they need professional nursing personnel to provide health care services and psychological support Health counseling, spiritual consolation and other professional services. At present, there is a huge gap in the number of interdisciplinary professionals who are proficient in computer technology and have professional medical literacy. At the same time, the mobility of service personnel is large, which is not conducive to the construction of professional talent team. The quality of smart pension service is not optimistic.

\subsection{Low Level of Intelligence -- the "Accuracy" of Absence}

At present, China's technology level and the development and manufacturing of intelligent devices are still in the primary stage. In the field of intelligent pension, compared with some foreign countries, the intelligent level is lower. On the one hand, the R \& D and manufacturing of high-end products such as intelligent service robots and mechanical exoskeletons need long-term technology accumulation. At present, 
the research and development of many key core software and hardware in China is still in the laboratory stage, far behind foreign enterprises. On the other hand, the technical $\mathrm{R} \& \mathrm{D}$ personnel know little about the pension industry and do not fundamentally understand the actual needs of the elderly. As a result, the intelligent products are "not intelligent". The elderly are far from comfortable in actual use and generally have low recognition.

\section{THE PRACTICAL PATH OF PROMOTING SMART PENSION}

China's smart pension model is still in the primary stage of development. Today, aging has entered a rapid stage, as a new pension model, it still needs to be improved and improved, so as to explore a smart pension model with Chinese characteristics.

\subsection{Accelerating the Bridging of the Silver Digital Divide}

The development of science and technology and social progress should not exclude the elderly, the elderly also have the right to enjoy the convenience of life. Under the normal development of the epidemic situation, we should first adhere to the principle of "walking on two legs", adhere to online and offline parallel, and balance the relationship between digital fast walkers and slow walkers. At the same time, the Internet websites and applications should be transformed to adapt to the aging, and the development of products that are easy to operate and more in line with the use habits of the elderly should be supervised. Secondly, we should encourage the development of information technology training for the elderly, improve their ability to use the Internet, and eliminate fear and exclusion. Finally, we should encourage family digital feedback and peer influence. On the one hand, we should play the role of family ties and encourage the younger generation to give digital feedback to the older generation. On the other hand, under the influence of peers, it can alleviate the panic of the elderly when learning digital technology and give them the social support they need [5].

\subsection{Strengthen Data and Information Security}

Network is a double-edged sword, which brings us great benefits, but it is also slowly stealing personal privacy information. In this regard, the government, as the leading force, should speed up the implementation of smart pension legislation, push it on the right track and play a good regulatory function. Strengthen the supervision of pension enterprises, institutions and pension operation platforms, severely punish data theft and leakage, increase the cost of crime, and effectively protect network security and privacy of the elderly.
Secondly, we should strengthen the level and regional integration, establish a standardized, unified and interactive data sharing system for smart pension, and realize the integration of information resources. Thirdly, we should strengthen technology research and development, fill in the vulnerability of product data security, and develop more private, safe and reliable intelligent service products. Finally, we should help the elderly learn network knowledge through various channels, popularize personal information security knowledge to the elderly, and enhance their information screening ability and information security awareness.

\subsection{Promote the "Temperature" of Smart Pension Products}

Intelligent pension is supported by the existence of precision, but in the face of indifferent intelligent machines, it is more necessary to have the warming of temperature. The "temperature" of smart pension emphasizes the humanity in the service, which should be more customized, such as providing customized services for the elderly according to the characteristics of region, resources and style, so that the initiative is in the hands of the elderly[6]. We can also transform the intelligent companion robot and other products, focusing on enhancing the dialogue and communication function and humanization, so as to overcome the coldness of the machine and the ruthlessness of the technology, and increase the temperature of the product. At the same time, we can organize regular exchanges and entertainment activities for the elderly to fully understand the intelligent products or services that the elderly are interested in and design exclusive intelligent products. So that the elderly can truly experience the warmth of intelligent products, rather than be out of reach.

\subsection{Strengthen the Construction of Compound Professional Talent Team}

To fill the gap of interdisciplinary talents, first of all, we should strengthen the construction of talent training mechanism, expand the scale of professional talent training, and strengthen the training of professional skills. We should support colleges and universities to set up courses related to smart pension, encourage students to participate, encourage medical nursing college students to master medical professional knowledge and be familiar with the use and maintenance of smart pension products, and strive to cultivate talents who can not only care for the body of the elderly and meet their emotional needs, but also proficient in technology. Secondly, the government and enterprises attract and retain talents through market-oriented means. Actively improve the salary and welfare level of professionals, and attract cross field high-end talents to enter the field of smart pension. Thirdly, we should strengthen the 
screening of service talents, set up strict management system and assessment mechanism, establish and improve the system of employment with certificates, and regularly carry out on-the-job training, so as to enhance the specialization of talent service team and provide more extensive and high-quality services.

\subsection{Enhancing the Accuracy Development of Products}

At present, the development of smart pension service in China is driven by the development of supply orientation. The development of smart pension service has appeared problems such as over rendering technology, neglecting service precision, and the discomfort of intelligent service products, and lack of attention to the real needs of the elderly. On the one hand, smart pension should be promoted to provide fine services, and heterogeneous services should be provided to the elderly of different ages, different educational backgrounds and different living habits. On the other hand, we should increase the investment in technology and the research and development of science and technology. The elderly are the main body of the elderly, and science and technology should serve the elderly. First, the state should focus on strengthening the policy inclination and subsidy for intelligent product $\mathrm{R}$ $\&$ D enterprises. Secondly, the government should guide the enterprises to improve technical support by formulating relevant policy documents, and develop high intelligent products that are more consistent with the physiological characteristics and cognitive level of the elderly, so that the elderly, especially the elderly and the disabled elderly, can enjoy comfortable and convenient services and enhance the living conditions A sense of living experience and acquisition.

\section{CONCLUSION}

With the development of the times, the way of providing for the aged should also be innovated. Like other age groups, the elderly also have the vision of a better life. As a brand-new pension model, smart pension is an innovative move in China's pension industry with its "new" Application of internet intelligent technology, the embedding of interactive technology and the guidance of brand-new values.
It is the common responsibility of the whole society to protect the legitimate rights and interests of the elderly. It needs the cooperation of the party, the state, the government, the community, and institutions. Through various and multilevel supplement and cooperation, we can timely adjust the policies and guidelines to help the elderly integrate into the world of big data Internet and help them gradually adapt to the smart pension model. Human beings can't stop the pace of time erosion, but they can guarantee that the faltering elderly also have the right to slow down in the era of rapid development of intelligence. I believe that in the process of continuous exploration and innovation, the level of pension in China will be improved step by step, and the elderly will be able to truly live a secure old age.

\section{ACKNOWLEDGMENTS}

Supported by National Social Science Foundation of China Key Project "Local practice of long-term care insurance system for disabled elderly" (Project No.: 17BRK015)

\section{REFERENCES}

[1] Hu Fan.Research on the development status and Countermeasures of smart pension [J]. Economic Research Guide, 2019(9): 49-50+108.

[2] Hu Liming, Wang Dongwei.New digital home care community solution $[\mathrm{J}]$. Intelligent building, 2007(11): 20-21.

[3] He Quan,Zhang Xiangdi.Influencing factors of digital divide for the elderly and social integration strategies [J]. Journal of Zhejiang University of Technology (Social Science Edition), 2017,16(04):437-441.

[4] $\mathrm{Hu}$ Yuhong.People-oriented legal deconstruction [J]. essays on politics and law, 2019(1):24-35.

[5] Liu Ruhao,Qiu Qian.Neglected peer influence in the digital divide of the elderly [J]. Young Journalists, 2020(36):31-32.

[6] Zhang Ruixin,Zhang Hao.Smart pension promotes the optimization of pension service system: ideas and approaches [J]. Administrative forum, 2020,27 (06): 139-145. 